\title{
PERBEDAAN LOMPAT JAUH GAYA JONGKOK, BERJALAN DI UDARA DAN MENGGANTUNG DI TINJAU DARI HASIL LOMPATAN PADA ATLET JUNIOR SUMATERA SELATAN
}

\author{
Riyan Pratama ${ }^{1)}$
}

\begin{abstract}
ABSTRAK
Penelitian ini bertujuan untuk mengetahui perbedaan lompat jauh gaya jongkok, berjalan di udara,dan menggantung ditinjau dari hasil lompatan. Metode dalam penelitain ini adalah survey. Populasi dalam peneltian ini berjumlah 15 orang atlet. Sampel penelitian ini diambil menggunakan teknik total sampling. Instrumen pengukuran menggunakan tes lompat jauh. Teknik analisis data yang digunakan adalah ANOVA satu jalur yang dilanjutkan dengan uji rentang Tukey pada taraf signifikansi $\alpha$ : 0,05. Hasil peneltian menunjukkan tidak ada perbedaan hasil lompat jauh gaya jongkok, berjalan diudara dan menggantung yang signifikan $(0,738>0.05)$. Pada kelompok sampel atlet junior lompat jauh sumatera selatan memiliki rata-rata lompatan terjauh menggunakan gaya beralan diudara.
\end{abstract}

Kata kunci: Lompat Jauh Gaya Jongkok, Berjalan di Udara, Menggantung

\begin{abstract}
This study aimed to determine the difference of sail style, hitchkick style, and hang style of long jump in terms of jump results. The method in this research is survey. The population in this study amounting to 15 athletes. The sample were taken using total sampling technique. All data were obtained through this study to test and measurement the using long jump test. The analysis data technique used is one-way ANOVA test followed by Tukey range test at significance level $\alpha: 0,05$. The results of this study indicate there is no significat difference in results of sail style,hitchkick style, and hang style of long jump a significant (0.738> 0.05). In south sumatera long jump junior athletes sample group had the furthest jump average using hitchkick style.
\end{abstract}

Keyword: sail style long jump, hitchkick style long jump, hang style long jump

\section{PENDAHULUAN}

Atletik merupakan cabang olahraga yang tertua yang telah ada dan dilakukan oleh manusia sejak jaman purba sampai sekarang ini. Bahkan dapat dikatakan sejak adanya manusia di muka bumi ini, atletik sudah ada dan dilakukan oleh manusia. Kata Atletik berasal dari kata Yunani yaitu Atlon, Atlun yang berati pertandingan atau perjuangan. Menurut Purnomo (2007: 3) Atletik adalah cabang olahraga yang paling tua dan juga merupakan induk dari semua

1) Riyan Pratama. Saat ini Dosen Universitas Bina Darma Palembang 
cabang olahraga yang gerakannya merupakan ragam gabungan dan pola gerak dasar hidup manusia sehari-hari. Ragam pola gerak yng dimaksut adalah berjalan, berlari, melompat dan melempar.

Dalam pendidikan jasmani (Penjas) atletik merupakan materi wajib yang diberikan dalam kurikulum pendidikan jasmani (Penjas). Selain dalam rangka pembelajaran, atletik di sekolah juga sebagai upaya meningkatkan daya tahan, kekuatan, kecepatan, kelincahan dan lain sebagainya bagi siswa. Pembelajaran Penjas merupakan salah satu muatan pendidikan dalam segala jenjang tingkatan pendidikan. Selain untuk keseragaman materi pendidikan, juga merupakan salah satu metode pencapaian sasaran pendidikan atau berusaha mencapai suatu taraf prestasi tertentu. Hal ini ditandai dengan sering diadakannya kejuaraan atau pertandingan yang mengikut sertakan 37 pelajar dan memperlombakan cabangcabang olahraga yang diantaranya adalah atletik. Nomor dalam cabang olahraga atletik antara lain nomor lintasan dan nomor lapangan. nomor lintasan itu sendiri terdiri dari lari (sprint) dan Jalan (run). Nomor Lapangan terdiri dari Lompat (jump) dan Lempar (throw).

Pada kurikulum pedidikan jasmani salah satu nomor atletik yang diberikan adalah lompat jauh. Dalam nomor ini atlet/siswa dituntut untuk melaompat sejauh mungkin pada bak pasir. Menurut Wiarto (2013: 32) Lompat jauh adalah suatu gerakan melompat yang diawali dengan gerakan horizontal dan diubah dengan gerakan vertical dengan jalan melakukan tolakan pada satu kaki yang terkuat untuk memperoleh jarak yang sejauh-jauhnya. Tujuan dari lompat jauh adalah melompat sejauh-jauhnya dengan memindahkan seluruh tubuh dari titik tertentu ketitik lainnya.Lompat jauh merupakan salah satu nomor lompat dalam cabang olahraga atletik. Lompat jauh adalah gerakan yang menggunakan tumpuan dengan satu kaki yang bertujuan untuk mencapai jarak yang sejauh-jauhnya.

Untuk mendapatkan lompatan yang optimal maka diperlukan teknik dalam melakukannya. Teknik merupakan unsur yang sangat penting yang harus dikuasai agar dapat berprestasi dalam olahraga termasuk lompat jauh. Penguasaan teknik yang baik akan memberikan keuntungan dan kegunaan dengan terjadinya efisiensi dan efektifitas gerakan untuk mencapai hasil optimal. Penguasaan teknik yang

1) Riyan Pratama. Saat ini Dosen Universitas Bina Darma Palembang 
baik juga akan dapat mengurangi kemungkinan terjadinya cedera, memberi perasaan lebih mantap dan percaya diri dalam penampilan. Lompat jauh merupakan rangkaian gerakan yang terdiri dari awalan, tumpuan, melayang di udara dan pendaratan.

Menurut Muller, H \& Ritzdorf (2000: 86) tentang teknik lompat terdiri dari empat tahap, yaitu awalan (Approach), tolakan (Take Off), melayang di udara dan pendaratan (Landing). Gerakan-gerakan dalam lompat jauh tersebut merupakan suatu rangkaian yang dilakukan secara harmonis, tidak terputus-putus atau secara berurutan di dalam pelaksanaannya. Unsur-unsur teknik lompat jauh tersebut diuraikan sebagai berikut :

1. Awalan

Tujuan dari awalan yaitu untuk mendapatkan kecepatan yang maksimal pada saat akan melompat dan membawa pelompat pada posisi yang optimum untuk melakukan tolakan. Awalan dalam lompat jauh dilakukan dengan berlari secepat-cepatnya. Hal ini sesuai dengan pendapat American Sport Education Program, 2008:133 bahwa untuk lari awalan lari dilakukan secepat-cepatnya tapi tetap terkontrol yang bertujuan agar tetap dapat melakukan tolakan dengan benar".

Awalan lompat jauh yang harus dilakukan dengan simultan dan dengan kecepatan maksimal. Jarak atau panjangnya awalan merupakan hal yang sangat penting yang perlu diperhitungkan jarak awalan yang perlu diambil adalah sedemikian rupa sehingga dengan jarak tersebut dapat memungkinkan untuk mendapatkan kecepatan yang maksimal. Panjangnya awalan dalam lompat jauh yaitu kira-kira 30-40 meter dari balok tumpuan.

2. Tumpuan atau Tolakan

Tumpuan merupakan gerak lanjutan dari kecepatan lari yang maksimal. Tumpuan dalam lompat jauh adalah menjejakkan salah satu kaki untuk menumpu tanpa langkah melebihi papan tumpu untuk mendapatkan tumpuan ke depan atas yang besar. Tujuan gerakan tumpuan ini adalah untuk merubah gerakan lari menjadi suatu lompatan. Pada tahap ini atlet membangkitkan kecepatan vertikal dan memperkecil hilangnya kecepatan horizontal (Muller, H \& Ritzdorf 2000:87)

3. Sikap badan di udara atau saat melayang

1) Riyan Pratama. Saat ini Dosen Universitas Bina Darma Palembang 
Pada saat melayang, pelompat harus berusaha untuk mempertahankan diri supaya tidak cepat jatuh ke tanah. Sehingga pada saat melayang sangatlah diperlukan keseimbangan tubuh yang baik. Pada saat itu keseimbangan harus dijaga jangan sampai terjatuh, bahkan kalau mungkin harus diusahakan membuat sikap atau gerakan untuk menambah jarak jangkauan lompatan. Dalam tahap ini atlet mempersiapkan diri untuk mendarat.

Perlu untuk diketahui bahwa gaya dan gerakan yang dilakukan di udara bukan untuk menambah jauhnya lompatan, akan tetapi hanya untuk menjaga keseimbangan dan mempertahankan pada saat pelompat malayang di udara selama mungkin.

4. Sikap mendarat

Pada waktu badan akan mendarat kedua tungkai harus diluruskan ke depan dan rapat, kedua lengan diayunkan ke depan bersamaan dengan membungkukkan badan ke depan. Pada saat jatuh di bak lompat, diusahakn jatuh pada kedua ujung kaki dan sejajar. Perlu dijaga dalam pendaratan jangan jatuh pada bagian pantat terlebih dahulu. Setelah mendarat dengan segera tubuh dibawa ke depan, agar tidak jatuh ke belakang.

Dalam lompat jauh, untuk dapat melompat sejauh mungkin maka terdapat cara atau gaya yang dapat digunakan sebagai pilhan yang dapat dipilih. Pada nomor lompat jauh ada tiga macam gaya, seperti yang dikemukakan oleh Syarifuddin (2002: 93) yaitu, "gaya-gaya lompat jauh yang umum dipergunakan itu adalah: gaya jongkok (Tuck), gaya menggantung (Hang style/schnepper) dan gaya jalan di udara (walking in the air)". Hal yang membedakan dari ketiga gaya terbut adalah pada sikap saat melayang diudara yang diharapkan mampu menambah jauhnya lompat seseorang.

Gaya jongkok (tuck jump) dikenal juga dengan sebutan gaya duduk di udara. Didalam gaya ini pada saat melayang di udara seorang pelompat melakukan seolah-olah membentuk sikap berjongkok di udara.

Pada lompat tinggai gaya gantung sikap diudara seolah-olah sedang menggantung diudara. Dari sikap di udara, kedua lengan luruskan ke depan kedua lutut dan badan dibawa ke depan. Saat kedua kaki akan menyentuh tempat 
pendaratan, luruskan ke depan dan mendarat dengan kedua tumit terlebih dahulu. Saat kedua kaki mendarat kedua lutut mengepet dan berat badan dibawa kedepan.

Lompat jauh gaya berjalan di udara adalah dimana gerakan lompat jauh dengan gaya seolah-olah sedang berjalan diudara, ketika tubuh sedang melayang di udara gerakan kaki seakan berlari atau berjalan di udara. Gerakan itu dilakukan setelah atlet melakukan tolakan dan tubuh sedang melayang di udara kedua kaki digerakkan seperti orang berlari sampai akhirnya landing kaki menyentuh tanah dan tubuh tetap dijatuhkan ke depan agar tidak mengurangi jauhnya lompatan.

Dalam proses pembelajaran pada mata pelajaran pendidikan jasmani olahraga dan kesehatan, aktivitasnya lebih banyak dilakukan di lapangan dibandingkan di dalam ruangan kelas. Hal ini sesuai dengan materi pada pembelajaran olahraga yang menuntut dilakukanya praktik dalam proses pembelajaran. Maka dari itu untuk mempraktikkan beberapa keterampilan olahraga dibutuhkan sarana dan prasarana yang mendukukung dimiliki sekolah, agar proses pembelajaran dapat berjalan dengan baik dan dapat mencapai setiap indikator pembelajaran.

Pada cabang olahraga atletik nomor lompat yaitu lompat jauh, membutuhkan dukungan dari sarana dan prasarana yang harus dipenuhi oleh sekolah agar prestasi lompat jauh dapat dicapai. Di sekolah-sekolah di Sumatera Selatan masih banyak sekolah, baik sekolah dasar (sd), sekolah menengah pertama (smp) hingga sekolah menengah atas (sma) yang belum memiliki saranaprasarana pendukung seperti bak pasir yang sesuai dengan standar. Kebanyakan yang tidak memiliki sarana prasana yang memadai tersebut adalah sekolahsekolah yang ada di daerah. Hal ini lah yang menjadi salah satu faktor yang menyebabkan kurangnya atlet potensial di Sumatera Selatan.

Keterbatasan ketersediaan tenaga ahli dibidang atletik khusus nya nomor lompat jauh yang membina bakal calon atlet lompat jauh juga menjadi faktor penyebab kurang nya atlet poitensial. Kebanyakan pelatih-pelatih yang membina cabang olahraga atletik khusus nya nomor lompat jauh belum terstandarisasi dan tersertifikasi dengan baik. Minat dan bakat atlet juga beperan dalam perkembangan cabang olahraga atlet khusus nya nomor lompat jauh, kebanyakan

1) Riyan Pratama. Saat ini Dosen Universitas Bina Darma Palembang 
anak usia sekolah lebih berminat pada cabang olahraga permainan, seperti sepak bola, futsal maupun bola basket.

Selain hal-hal tersebut diatas, dari segi teknik, masih belum diketahui dengan jelas teknik atau gaya dalam lompat jauh yang mana yang memiliki efektifitas yang paling baik apabila digunakan dalam melakukan lompat jauh. Berdasarkan hal tersebut maka penulis terdorong untuk meneliti perbedaan lompat jauh gaya jongkok, berjalan diudara dan menggantung di itinjau dari hasil lompatan

\section{METODOLOGI}

Penelitian ini adalah penelitian deskriptif kuantitatif dengan metode survey, dimana penelitian ini bertujuan untuk menggungkapkan sesuatu apa adanya. Sebagaimana yang dikemukakan (Arikunto 2014: 310) bahwa penelitian deskriptif adalah penelitian yang tidak bermaksud untuk menguji hipotesis tertentu tetapi hanya menggambarkan apa adanya tentang suatu variabel, gejala dan keadaan tertentu. Tempat penelitian ini dilakukan di Stadion Atletik Jakabaring Palembang pada bulan Maret 2017.

Populasi penelitian ini adalah keseluruhan atlet junior daerah Sumatra Selatan yang berusia 15 tahun (Kelas 1 SMA) yang berlatih di Stadion Atletik Jakabaring Palembang yang berjumlah 15 orang atlet. Sampel dalam penelitian ini menggunakan teknik total sampling dimana jumlah sampel yang digunakan berjumlah 15 orang atlet

Untuk memperoleh data yang diperlukan dalam penelitian ini diadakan tes dan pengukuran. Diantaranya meliputi tes lompat jauh gaya jongkok, berjalan diudara dan menggantung bagi atlet atletik nomor lompat jauh daerah Sumatra Selatan.

Teknik analisis data yang digunakan dalam penelitian ini dengan menggunakan SPSS 20 yaitu Analisis Varian (ANAVA) satu jalur pada taraf signifikansi $\alpha=0,05$. Untuk memenuhi asumsi ANAVA maka dilakukan uji normalitas dengan Ko dan homogenitas dengan uji Levene Test menggunakan program software SPSS version 20.0 for windows.

1) Riyan Pratama. Saat ini Dosen Universitas Bina Darma Palembang 


\section{HASIL PENELITIAN}

Hasil yang diperoleh dari penelitian berupa data yang merupakan gambaran umum tentang masing-masing variabel yang terkait dalam penelitian. Berikut hasil dari tes lompat jauh yang dimiliki oleh atlet atletik nomor lompat jauh daerah Sumatra Selatan:

\section{Tabel 1. Deskripsi data Penelitian}

\begin{tabular}{|l|l|l|l|}
\hline No & Gaya lompat Jauh & Statistik & Hasil \\
\hline 1 & Gaya Jongkok & Mean & 5,96 \\
\cline { 3 - 4 } & & SD & 0,41 \\
\hline 2 & Berjalan di Udara & Mean & 5,99 \\
\cline { 3 - 4 } & & SD & 0,10 \\
\hline 3 & Menggantung & Mean & 5,88 \\
\cline { 3 - 4 } & & SD & 0,18 \\
\hline
\end{tabular}

Analisis Data

Uji Normalitas

Tabel 2. Deskripsi uji normalitas

\begin{tabular}{|l|l|l|l|}
\hline Data & P & $\begin{array}{l}\text { Taraf } \\
\text { Signifikansi }\end{array}$ & Keterangan \\
\hline Gaya Jongkok & 0,200 & \multirow{2}{*}{0,05} & Normal \\
\cline { 1 - 2 } Berjalan di Udara & 0,200 & & Normal \\
\cline { 1 - 2 } Menggantung & 0,165 & & Normal \\
\hline
\end{tabular}

Uji Homogenitas

Tabel 3. Deskripsi Uji Homogenitas

\begin{tabular}{|l|l|l|l|l|l|}
\hline Vatiabel & $\begin{array}{l}\text { Lavene } \\
\text { Statistic }\end{array}$ & df1 & df2 & Sig. & Keterangan \\
\hline $\begin{array}{l}\text { Gaya Lompat } \\
\text { Jauh }\end{array}$ & 5,229 & 2 & 12 & 0,05 & Homogen \\
\hline
\end{tabular}

1) Riyan Pratama. Saat ini Dosen Universitas Bina Darma Palembang 
Uji Hipotesis

Tabel 4. Uji ANOVA Satu Jalur

\begin{tabular}{|l|l|l|l|l|l|}
\hline Sourse & $\begin{array}{l}\text { Sum of } \\
\text { Squares }\end{array}$ & df & $\begin{array}{l}\text { Mean } \\
\text { Square }\end{array}$ & F & Sig \\
\hline $\begin{array}{l}\text { Gaya } \\
\text { Lompatan }\end{array}$ & 0,036 & 2 & 0,018 & 0,245 & 0,786 \\
\hline
\end{tabular}

Berdasarkan hasil tabel penghitungan diketahui ada perbedaan hasil lompatan antara gaya jongkok, berjalan diudara dan menggantung pada atlet daerah lompat jauh Sumatra Selatan. Hal ini dibuktikan dari nilai signifikansi sebesar 0,786 > 0,05 yang berarti bahwa lebih besar dari taraf signifikan. Dengan demikian berarti gaya jongkok, berjalan diudara dan menggantung tidak memiliki hasil yang berbeda antara gaya satu dan yang lainnya. Dari analisis lanjutan diperoleh bahwa ternyata gaya berjalan diudara memiliki hasil lompatan yang paling baik dari pada gaya jongkok pada urutan kedua dan gaya menggantung di urutan ketiga.

\section{PEMBAHASAN}

Pembahasan hasil penelitian memberikan penafsiran lebih lanjut mengenai hasil-hasil analisis data yang telah di kemukakan. Berdasarkan pengujian hipotesis yang berbunyi "tidak terdapat perbedaan hasil lompatan antara gaya jongkok, menggantung dan berjalan diudara”. Dari ketiga teknik tersebut secara teknik memilki perbedaan, perbedaan ketiga gaya ini terletak pada sikap diudara.Pada gaya jongkok kaki tumpuan tetap tegak keatas dan vertikal, kaki tumpuan mengikuti selama selama waktu melayang, dan kemudian kedua kaki diluruskan untuk mendarat. Pada menggantung posisi pinggang didorong kedepan, kedua kaki paralel dengan telapak kaki menggadap kebelakang tangan diatas seolah-olah sedang menggantung dan mendekati akhir lompatan kedua kaki didorong sejauhjauhnya kedepan dengan lengan bergerak seperti mendayung secara bersamaan. Sedangkan pada gaya berjalan diudara secara teknis meneruskan gerakan lari akan 
tetapi dilakukan diudara dengan didukung oleh ayunan lengan, gerakan ini harus berakhir pada saat mendarat dengan kedua kaki diluruskan ke depan.

Berdasarkan hipotesis tersebut diketahui tidak terdapat perbedaan hasil lompatan menggunakan ketiga gaya tersebut. Selain dari segi teknis, dari segi kualitas otot juga sangat berperan penting dalam menentukan jauh tidaknya lompatan seseorang. Kualitas otot yang di maksud adalah kualitas otot ekstrimitas bawah yang berperan melakukan lompatan.

Apabila dicermati lebih lanjut dari ketiga gaya tersebut, gaya berjalan diudara memiliki rata-rata lompatan terbanyak yang memiliki jarak yang jauh dibanding gaya jongkok dan gaya menggantung. Hal tersebut dikarenakan faktor kebiasaan dari masing-masing atlet. Dari 15 atlet yang menjadi sampel penelitian 10 atlet memang selalu memakai gaya berjalan diudara pada lompatan terjauh nya, walaupun lopatan terjauh yaitu dengan jauh lopatan 6,51m menggunakan gaya jongkok.

\section{KESIMPULAN}

Secara praktis hasil penelitian ini dapat digunakan sebagai bahan acuan bagi pelatih lompat jauh sumatera selatan dalam menentukan gaya yang akan dimaksimalkan juga sebagai salah satu bahan acuan dalam membuat program latihan dalam membina atlet maupun calon atlet yang akan berlomba di tinggkat daerah, provinsi maupun nasional di Sumatera Selatan.

Untuk para peneliti yang bermaksud melanjudkan atau mereplikasi penelitian ini disarankan untuk melakukan kontrol lebih ketat, kotrol yang dimaksud adalah peneliti harus mengetahui fase dari program latihan yang sedang dilankan oleh atlet maupun pelatih yang menjadi sampel penelitian guna menghindari ancamab dari validatas eksternal maupun internal.

\section{REFERENSI}

Aip Syarifuddin. 2002. Atletik. Jakarta: Depdikbud.

American Sport Education Program, 2008:13. Coaching Youth track \& field). Champaign. Human Kinetics

1) Riyan Pratama. Saat ini Dosen Universitas Bina Darma Palembang 
Eddy Purnomo. (2007). Pedoman Mengajar Dasar Gerak Atletik Yogyakarta: Universitas Negeri Yogyakarta.

Muller, H \& Ritzdorf. (2000). Pedoman Resmi Mengajar Atletik level 1. Jakarta. IAAF-RDC.

Wiarto, Giri.2013. Atletik. Yogyakarta. Graha Ilmu. 